\title{
Physiological basis of improvement after lung volume reduction surgery for severe emphysema: where are we?
}

\author{
E. Marchand, G. Gayan-Ramirez, P. De Leyn, M. Decramer
}

Physiological basis of improvement after lung volume reduction surgery for severe emphysema: where are we? E. Marchand, G. Gayan-Ramirez, P. De Leyn, M. Decramer. (C) ERJ Journals Ltd 1999.

ABSTRACT: Lung volume reduction surgery has become an accepted therapeutic option to relieve the symptoms of selected patients with severe emphysema. In a majority of these patients, it causes objective as well as subjective functional improvement. A proper understanding of the physiological determinants underlying these beneficial effects appears very important in order to better select patients for the procedure that is currently largely carried out on an empirical basis.

Lung volume reduction surgery has two distinct effects. Firstly, it causes an increased elastic recoil, which at least partially explains the enhanced maximal expiratory flow. Secondly, it is associated with a reduction of hyperinflation which allows for an increase in global inspiratory muscle strength and in diaphragmatic contribution to tidal volume as well as a decrease in the inspiratory elastic load imposed by the chest wall. Taken together, these effects result in a reduced work of breathing and in an enhanced maximal ventilation which both contribute to the increased exercise capacity and reduced dyspnoea after surgery. The improved lung recoil and the reduced hyperinflation after volume reduction surgery were the primary postulates upon which the usual selection criteria for the procedure were based. It is now likely that these are correct. Nevertheless, some patients do not benefit from lung volume reduction surgery and the current literature does not allow for a refinement of the selection process from a physiological point of view.

The exact mechanisms underlying the improvement in lung recoil, lung mechanics, and respiratory muscle function remain incompletely understood. Moreover, the effects of lung volume reduction surgery on gas exchange and pulmonary haemodynamics still need to be more fully investigated. An analysis of the characteristics of patients who do not benefit from the procedure and the development of an animal model for lung volume reduction surgery would probably help address these important issues.

Eur Respir J 1999; 13: 686-696.

Lung volume reduction surgery (LVRS) is one of the newest therapeutic options for patients with severe emphysema. Originally proposed by BRANTIGAN et al. [1] in the 1950 s, the concept only received widespread acceptance in the medical community after its revival by the groups of J.D. Cooper [2] and A.Wakabayashi [3, 4]. LVRS is now performed in various centres throughout the world. In a majority of selected patients, this technique has been shown to improve subjective as well as objective variables in a way not obtainable by any other currently available therapy. In spite of these encouraging results, some patients do not benefit from the procedure. Moreover, the selection of patients for surgery remains largely empirical and longterm results are still lacking, which has led some to raise criticisms regarding the widespread application of the procedure [5].

For editorial comments see page 480
Respiratory Muscle Research Unit, Laboratory for Pneumology and Respiratory Division and Dept of Thoracic Surgery, University Hospital, Katholieke Universiteit Leuven, Leuven, Belgium.

Correspondence: M. Decramer Respiratory Division University Hospital Herestraat 49

B-3000 Leuven

Belgium

Fax: 3216347126

Keywords: Emphysema

gas exchange

haemodynamics

lung mechanics

lung volume reduction surgery

respiratory muscles

Received: July 51998

Accepted after revision July 131998

Supported by Fonds voor Wetenschappelijk onderzoek-Vlaanderen grants 3.0167.95 and G.0189.97
A proper understanding of the pathophysiological basis for subjective and objective improvements after LVRS is important for improving the selection of patients. Selection is important as only $20-40 \%$ of patients referred for surgery are real candidates, only $50-75 \%$ of patients improve with the intervention, and mortality still ranges $4-17 \%$ [6]. In addition, a better insight into the mechanism of improvement may lead to further development of the surgical procedure. The aim of this article is to provide a critical analysis of the literature regarding the potential mechanisms of action of LVRS. The term LVRS generally encompasses a variety of surgical procedures intended to alleviate the symptoms of advanced emphysema. However, in the following, its utilization will be restricted to the resection of diffusely emphysematous tissue, in contrast to the excision of giant bullae. Although this distinction is sometimes subtle in subjects presenting bullae in the context of an accompanying generalized emphysema, series of patients who have undergone bullectomy are often more 
difficult to analyse because of a greater heterogeneity in the severity of respiratory dysfunction. Moreover, the mechanisms underlying the functional outcome after surgery are likely to be more complex with LVRS than with bullectomy.

\section{Pathophysiological basis of functional impairment in emphysema}

Emphysema is defined anatomically by abnormal, persistent enlargement of the air spaces distal to the terminal bronchioles, accompanied by the destruction of the alveolar walls in the absence of obvious fibrosis [7]. The direct physiological consequence of these abnormalities is a loss of elastic lung recoil reflected in a leftward shift of the lung pressure--volume $(P-V)$ curve. The loss of elastic recoil results in a lower maximal expiratory airflow because of reduced driving pressure [8] and impaired radial traction on the airways leading to a reduction of their calibre [9]. It must be stressed that in its advanced stage, emphysema is always associated with intrinsic airway disease $[10,11]$ which clearly also contributes to airflow obstruction. Altogether and whatever the cause, the above factors result in low expiratory flow, not allowing sufficient time for expiration. This leads to termination of the expiration above the resting volume of the respiratory system. Consequently, dynamic hyperinflation [12], and hence the generation of intrinsic positive end-expiratory (alveolar) pressure (intrinsic PEEP) occurs [13]. Along with the loss of elastic lung recoil, dynamic hyperinflation leads to an increase in the lung volume at which the respiratory muscles operate. This puts the muscles at a mechanical disadvantage.

The mechanical effectiveness of the diaphragm is reduced because of multiple effects of hyperinflation on its length and geometry. Firstly, the length of the diaphragm at functional residual capacity (FRC) is reduced with chronic hyperinflation [14]. Theoretically, this is expected to place the diaphragm at a less favourable part of its lengthtension curve. However, it has been shown in animal models of emphysema that the diaphragm adapts to chronic hyperinflation by a loss of sarcomeres in series. This is called length adaptation. It results in a shift of the whole length-tension curve to a shorter length. As a consequence, a match between the in situ operational length and the optimal length remains with chronic hyperinflation [15]. There is indirect evidence that this may also occur in patients with chronic obstructive pulmonary disease (COPD) who are able to develop a greater maximal negative inspiratory pressure than normal subjects at a given lung volume [16]. Secondly, in patients with chronic hyperinflation, the zone of apposition, which is the area of the diaphragm immediately apposed to the ribcage, is markedly reduced at FRC [14]. Figure 1 illustrates the consequences of hyperinflation on diaphragm geometry in a normal subject. Similar three-dimensional reconstruction has yielded the same findings in COPD patients [17]. Moreover, the cranial orientation of the diaphragmatic fibres at their costal insertion may also be affected. These points are critical for two major actions of the diaphragm, i.e. the piston-like axial displacement of the diaphragmatic dome which produces the main contribution of the diaphragm to tidal volume in normal subjects, and the expansion of the lower ribcage [18]. As the size of the
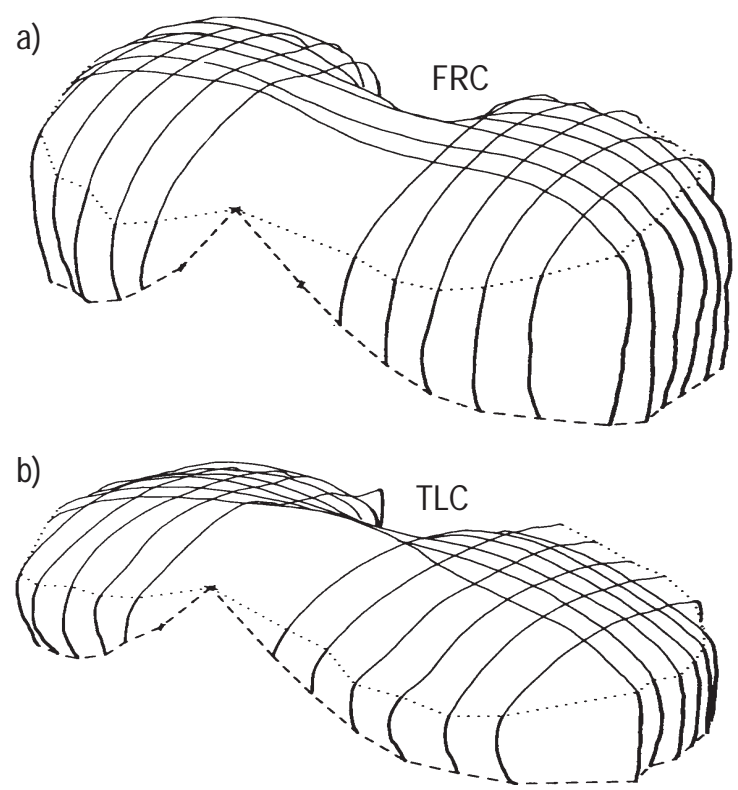

Fig. 1. - Three-dimensional reconstruction of the diaphragm at a) functional residual capacity (FRC) and at b) total lung capacity (TLC) in a normal male. It can easily be seen that the vertical portion of the diaphragm at its periphery, which can be approximated as the zone of apposition, is largely reduced by hyperinflation from FRC to TLC. The overall geometry of the diaphragm, however, changes little between FRC and TLC. (From Gauthier et al. [17] with permission.)

zone of apposition is reduced, and the orientation of the muscular fibres at the site of their costal insertion is possibly disturbed with hyperinflation, this potentially reduces the ability of the diaphragm to generate inspiratory volume change. Thirdly, it has been hypothesized that hyperinflation could change the mechanical arrangement between the crural and the costal parts of the diaphragm from a parallel to a series arrangement, thus leading to a reduction of the force-generating capacity [19]. Furthermore, it is often argued that hyperinflation is associated with an increased diaphragmatic radius of curvature which, according to Laplace's law, would result in a reduced conversion of active tension into pressure. Using three-dimensional reconstruction of the diaphragm, GAUTHIER et al. [17] showed that the radius of curvature was only altered by hyperinflation in the coronal plane but changed little in the sagital plane (fig. 1). Globally, these changes in curvature have played only a minimal role in the reduction of transdiaphragmatic pressure induced by supramaximal phrenic shocks in the setting of acute hyperinflation, which was mostly related to shortening [17]. All in all, the mechanical effectiveness of the diaphragm is markedly reduced by severe hyperinflation.

Although the effects of hyperinflation on other inspiratory muscles seem to be critical for inspiratory flow generation in hyperinflated patients, they have been less well studied. The mechanical effectiveness of the parasternal intercostals (the most important inspiratory part of the intercostal musculature) appears to be decreased by hyperinflation, at least in dogs [20]. These negative effects are more likely due to the alteration of their geometry rather than their length. In the dog, hyperinflation seems to induce a relatively small shortening of the parasternal intercostals compared to the diaphragm [21]. Moreover, their optimal operational length is closer to total lung capacity 
(TLC) than to FRC [22]. Nevertheless, these potential beneficial effects are probably counterbalanced by geometrical alterations. Indeed, the mechanical advantage of the parasternal intercostals has been shown to depend on the relationship between the angle formed by the costal cartilage and the sternum $(\alpha)$ and the angle between the muscle fibres and the sternum ( $\beta$ ) [21]. By increasing $\beta$ [23], hyperinflation potentially reduces the parasternal intercostal mechanical advantage. Moreover, following Laplace's law, the increased ribcage diameter [24] is another factor that might explain the decreased effectiveness of these inspiratory muscles with hyperinflation.

Much less is known about the effects of hyperinflation on the scalenes and sternomastoid muscles. The former are important primary inspiratory muscles [25] that experience increased effective central neural drive in patients with COPD compared with normal subjects, as do the parasternal intercostals [26]. Although hyperinflation has little effect on their length in the dog [27], its consequences on the mechanical effectiveness of human scalenes are not known. Knowledge regarding the mechanical effectiveness of the human sternomastoid as an inspiratory muscle is also lacking but it does not appear to be an important inspiratory muscle in normal subjects and COPD patients at rest [26].

In patients with severe COPD, expiration is often associated with contraction of the abdominal muscles [28]. This may lead to a paradoxical rise of gastric pressure during expiration and is an important determinant of intrinsic PEEP [29]. Moreover, variation in abdominal muscle recruitment may explain why some patients adjust their thoracoabdominal structures to accommodate increased lung volume by mainly expanding the bony ribcage whereas this is accomplished by lowering the diaphragm in others [30]. In the setting of flow limitation, abdominal muscle contraction is clearly inefficient in generating expiratory flow. However, it might have beneficial effects on inspiration. Firstly, it stores elastic and gravitational energy in the abdominal compartment that can be released during inspiration, performing inspiratory work without increasing transdiaphragmatic pressure [31, 32]. Secondly, it may keep the crural and the costal parts of the diaphragm arranged mechanically in parallel and place it on a more favourable part of its length-tension curve [32]. However, it has been argued that since the contraction of the abdominal muscles ends abruptly at the end of expiration, these beneficial effects on diaphragm length and geometry are lost as soon as inspiration begins [33].

Hyperinflation not only reduces the mechanical effectiveness of the diaphragm and probably also of the other inspiratory muscles, but when severe it also results in an inward chest wall recoil at end-expiration [18]. This, together with increased airway resistance, reduced dynamic pulmonary compliance, and true alveolar intrinsic PEEP imposes an important load on the inspiratory muscles. This load is even greater during exercise because of increased ventilatory requirements, thereby leading to further dynamic hyperinflation and a reduction of the duty cycle.

Abnormalities in resting blood gases appear only late in the course of emphysema. They are mostly related to ventilation-perfusion mismatching [34]. However, during exercise, other mechanisms also add to the alterations in the blood gases, i.e. diffusion abnormalities and increased dead space ventilation [35]. Moreover, hypoxaemia may also be related to a fall in mixed venous oxygen tension
$\left(P_{\mathrm{v}}^{-} \mathrm{O}_{2}\right)$ due to altered cardiac function. This fall may be related to altered venous return, cardiac filling, pulmonary hypertension, or increased respiratory muscle oxygen consumption [36].

Exercise capacity, either maximal or submaximal, is reduced in emphysema. Ventilatory limitation clearly plays a major role in exercise limitation. Nevertheless, peripheral muscle function is also recognized as an important determinant of exercise limitation [37]. As peripheral muscle weakness secondary to inactivity, denutrition, or corticosteroid therapy is frequently present in patients with COPD [37], this must be taken into account when considering exercise limitation in patients with emphysema.

Dyspnoea is an important determinant of quality of life in emphysema [38]. The mechanisms underlying breathlessness remain incompletely understood. Nevertheless, it appears that the sensation of dyspnoea is mostly related to the perception of inspiratory muscle effort, which can be estimated by the ratio of inspiratory muscle pressure developed during tidal breathing to the maximal inspiratory muscle strength [35].

\section{Overview of the results of lung volume reduction surgery on pulmonary function, exercise capacity, and dyspnoea}

Numerous studies are now available regarding the shortterm results of LVRS on pulmonary function and dyspnoea. These are difficult to compare for several reasons. Firstly, selection criteria varied from centre to centre, particularly regarding the characteristics of emphysema, with certain studies limited to homogeneous emphysema and others even including cases of true bullectomy. Secondly, studies were rarely prospective and often concerned selected cases. Thirdly, the surgical techniques used were varied (unilateral versus bilateral; sternotomy versus thoracoscopy or lateral thoracotomy; and staples versus laser), sometimes even in the same study. Fourthly, although pulmonary rehabilitation is often performed in the preoperative and postoperative period, the components of these rehabilitation programmes are rarely clearly described.

Nevertheless, an overview of the results available in the literature shows that, in the majority of selected patients, LVRS leads to a short-term (1-3 months post-surgery) improvement in forced expiratory volume in one second (FEV1) and vital capacity (VC), either forced or inspiratory $[4,39-60]$. Moreover, there is a decrease in TLC, in FRC and in residual volume (RV) measured by plethysmography $[4,39,41-44,49-51,53,54,56-60]$. In one study [48] reporting the results of static lung volumes, TLC was not significantly reduced after unilateral thoracoscopic LVRS using a stapling device. Nevertheless, RV was significantly reduced after the surgical procedure in this study [48]. Volumes measured by dilution techniques have only scarcely been reported. HALZERIGG et al. [39] reported unchanged FRC measured by nitrogen washout after unilateral laser pneumoplasty while CoRDOva et al. [59] demonstrated a reduction after bilateral stapling volume reduction. Besides FEV1, more specific indices of airflow obstruction have been reported less frequently. Three groups reported improved $\mathrm{FEV} 1 / \mathrm{VC}$ ratios, using stapling techniques and with most patients operated on bilaterally $[52,61,62]$. Others found a lack of significant improvement in $\mathrm{FEV} 1 / \mathrm{VC}[4,48,53,59]$. When reported, airway 
resistance and specific airway conductance were always improved after surgery [4, 53, 56, 59, 63, 64].

It has been claimed that LVRS had no effect on diffusion indices [65]. Recent reports, however, have showed significantly improved carbon monoxide transfer factor $(T \mathrm{~L}, \mathrm{CO})$ in some studies $[4,50,54,60,66]$, while in others there was a tendency towards improvement $[39,48,51,53$, 67]. Overall, this suggests that LVRS may lead to recruitment of the capillary bed. Reports of carbon monoxide transfer coefficient $(K \mathrm{CO})$ did not show significant shortterm improvement $[39,53,59,66]$.

LVRS appeared to improve blood gases at rest. Indeed, arterial oxygen tension $\left(\mathrm{Pa}_{\mathrm{a}} \mathrm{O}_{2}\right)$ increased in all studies reporting this variable $[4,39,41-45,48,50,52-54,56-58$, $67,68]$, although the improvement was only statistically significant in half of the studies $[42,45,48,50,53,56,58$, 68]. Similarly, arterial carbon dioxide tension $\left(P_{\left.\mathrm{a}, \mathrm{CO}_{2}\right)}\right)$ either showed a tendency to decrease $[4,39,43,44,48,52$, $53,56,58]$ or a statistically significant decrease $[41,42,45$, $54,57,67,68]$.

Submaximal exercise performance has often been evaluated by means of a six or twelve-minute walking tests. The distance walked always improved significantly after LVRS [39, 40, 42, 43, 48, 49, 51, 54, 56, 59, 67-69]. Nevertheless, a majority of patients underwent pulmonary rehabilitation at least preoperatively and this clearly may have contributed to this improvement. Moreover, some patients were walking with oxygen supplementation, which also might have affected results.

Maximal exercise capacity evaluated by peak exercise oxygen consumption $\left(V^{\prime} \mathrm{O}_{2}\right.$,max $)$ has been shown to increase in four studies [41, 42, 48, 59], including one enrolling subjects who did not follow any training programme [41]. By way of contrast, O'Donnell et al. [53] did not find any improvement in $V^{\prime} \mathrm{O}_{2}$, max in a heterogeneous group of patients, despite postoperative rehabilitation. Dyspnoea, evaluated by variable means, has also been shown to decrease after LVRS [39-43, 45, 47, 48, 50, 51, 53, 54, 56, $57,60,69]$.

A few studies have prospectively assessed the effects of LVRS on quality of life using validated questionnaires. These reported a significant short-term improvement after surgery $[2,39,59,70]$.

\section{Potential determinants of early functional improvement after lung volume reduction surgery}

\section{Static mechanics of the respiratory system}

Three different groups have reported improvement of indices of lung elastic recoil after LVRS using expiratory $P-V$ curves in awake subjects $[51,66,67,71]$. They all showed an increase in static lung elastic recoil pressure at total lung capacity ( $P$ L,st,TLC).

Gelb et al. [71] did not show a significant decrease in static lung compliance between FRC and FRC plus 0.4 L. Nevertheless, the same group reported an increased elastic lung recoil pressure between end-expiratory lung volume (EELV) and EELV plus 1,150 mL in patients under general anaesthesia and muscle paralysis immediately after the surgical procedure [63]. However, it might be supposed that the acute trauma of surgery has a transient effect on the lung mechanics. An increased static transpulmonary pres- sure was also demonstrated in awake patients at FRC 6 and 12 months after LVRS [66].

The accuracy of measurement of the $P-V$ curve in patients with severe emphysema has been questioned because there is doubt about the validity of plethysmographic lung volume measurements [72], the accuracy of local oesophageal pressure in reflecting overall pleural pressure [72], and the capacity of the patient to achieve the adequate relaxation required for the measurements. Another problem is associated with the fact that there is no simple index of lung elasticity. In this regard, it must be remembered that $P \mathrm{~L}, \mathrm{st}, \mathrm{TLC}$, as reported in the aforementioned studies not only reflects the elastic properties of the lung but is also influenced by the pressure generated by the inspiratory muscles and the chest wall compliance. As the reduction in TLC puts the inspiratory muscles at a mechanical advantage, the absence of increase in PL,st,TLC would imply either a decreased inspiratory muscle strength, or a decreased chest wall compliance after LVRS. Similarly, the shift rightwards and downwards of the $P-V$ curve also reported after LVRS, with volume expressed in absolute terms $[66,71]$ or in per cent predicted TLC [67], is a usual feature after lung resection [73]. This shift would be more relevant if it was shown to occur with volume expressed as a percentage of actual TLC.

Nevertheless, the demonstration of an increased static transpulmonary pressure at FRC is strong evidence for a definite favourable effect of LVRS on lung elastic recoil. The mechanisms whereby it is achieved remain, however, poorly understood. Some have hypothesized that severely emphysematous lung areas do not participate in the leftward shift of the $P-V$ curve that occurs in emphysema [72] because they do not change volume during a VC manoeuvre and would thus only account for a shift of the curve upwards. This may be true for real bullae [74]. Conversely, excluded bullous zones may indirectly cause a leftward shift of the $P-V$ curve by inappropriately transmitting the recoil pressure to the surrounding lung tissue. The removal of diseased lung could therefore improve airway tethering through the better transmission of the recoil pressure [75]. Such a hypothesis implies that patients with heterogeneous emphysema would benefit more from an intervention targeted at removing the more affected areas than patients with more homogeneous forms of the disease. This is supported by preliminary results showing that patients with inhomogeneous emphysema on imaging demonstrate greater FEV1 improvement after LVRS [76, 77].

The improved lung elastic recoil is expected to play a role in the improvement of airflow. If it is assumed that the relationship between elastic lung recoil and maximal airflow remains unaltered after the surgical procedure, for each volume in reference to FRC, the flow will be greater after than before surgery owing to increased lung recoil (fig. 2). However, the relationship between lung elastic recoil and maximal expiratory flow appears to be altered after LVRS, at least in some patients $[66,71]$. This means that, along with allowing an increased driving pressure, the greater elastic recoil may in addition increase the airway diameter by improved airway tethering. Conversely, factors other than elastic recoil may also play a role in the improved airway conductance. This is supported by the findings of RoGERs et al. [78] who studied the relationship between airway conductance and lung elastic recoil at different volumes in 14 patients. Using this technique, it 

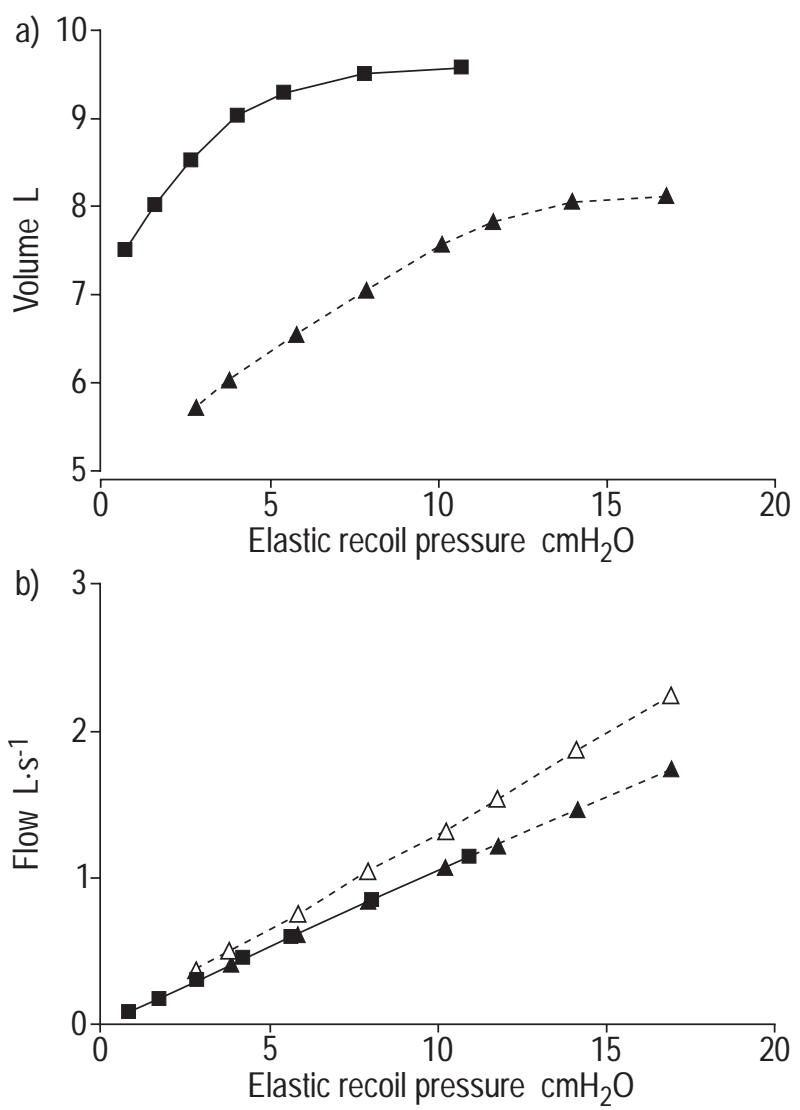

appeared that in half of their subjects, the improved airway conductance at a given volume after LVRS was entirely explained by the improved elastic recoil. Nevertheless, some patients demonstrated a greater increase in conductance than expected on the basis of the increase in lung recoil after surgery. Similarly, PRIDE et al. [74] also reported improved FEV1 after bullectomy in patients who did not show any improvement in lung elasticity measurements. These findings may be due to the inability of the $P-V$ curve to account for complex locoregional heterogeneity in mechanical and airway properties. Conversely, it may be suggested that LVRS, as does bullectomy, allows the decompression of relatively more normal lung areas, and thereby leads to: 1) a recruitment of effective lung volume; 2) a modification of airway geometry that may reduce airway obstruction; and 3) an improvement of surfactant synthesis in the better inflated, formerly compressed zones, which may also concur with better airway patency [79].

Chest wall mechanics are more difficult to assess because the achievement of a perfect relaxation of the respiratory muscles is not realistic in severely emphysematous patients. Measurement of chest wall recoil therefore requires muscle paralysis. GelB et al. [63] described a decreased inward chest wall recoil immediately after LVRS. However, they were unable to measure FRC and thus the decreased chest wall recoil pressure at EELV may solely reflect the decrease in FRC. Nevertheless, it obviously contributes to the decrease in work of breathing through a lower burden on the inspiratory muscles. It also leads to a decrease in the end-expiratory pleural pressure, as demonstrated in some studies [51, 61, 67].
Fig. 2. - Theoretical relationship between a) the volume-elastic recoil curve, b) the flow-elastic recoil curve and c) the flow-volume curve, before (- - ) and after (- - -) lung volume reduction surgery. A distinction is made between unaltered $(\boldsymbol{\Delta})$ and improved $(\Delta)$ maximal expiratory flow-elastic recoil relationship in (b).

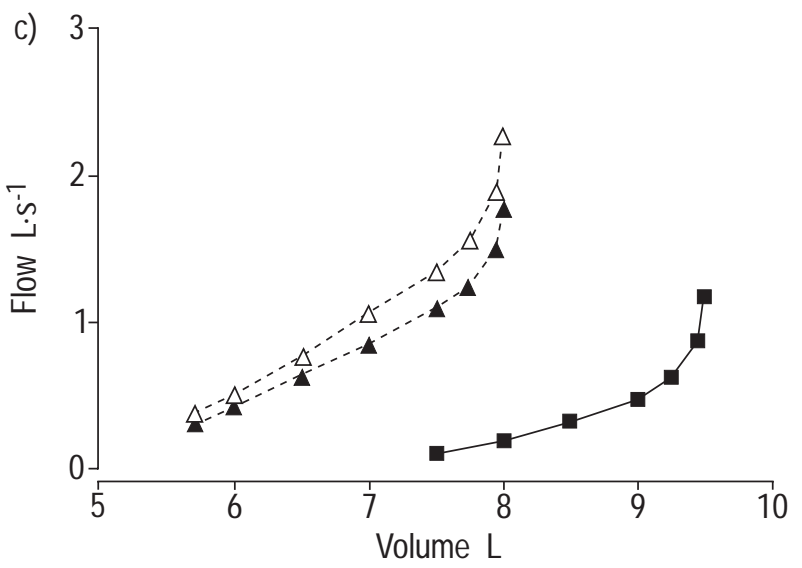

Dynamic lung mechanics

TSCHERNKO et al. [64] demonstrated an increase in lung dynamic compliance that was evident from the first postoperative day and persisted after 6 months. The absence of modifications in breathing frequency, minute ventilation, or breathing pattern further supported the significance of this observation. Since the static lung compliance in the tidal volume range has been shown to be unaltered by LVRS [71], the increased dynamic compliance suggests that more homogeneous ventilation in the lung was achieved after LVRS, which was also reflected in a decreased intrinsic PEEP [64]. Nevertheless, as stated above, in patients with severe COPD, expiration is often associated with contraction of the abdominal muscles that ends before the start of inspiratory flow. This is an important determinant of intrinsic PEEP in such patients [29]. As end-expiratory gastric pressure was shown to decrease after LVRS in one study [61], probably signalling a derecruitment of abdominal muscles during expiration, improvement in dynamic lung mechanics is not likely to be the only determinant of decreased intrinsic PEEP after LVRS.

A more even and better distribution of ventilation was also suggested by the finding of an improved single breath volume distribution of inhaled methane gas tracer after LVRS [80]. In addition to the reduced functional lung volume which allows ventilation on a more optimal portion of the chest wall $P-V$ curve, these elements contribute to a reduced work of breathing. This is obtained from the first postoperative day onwards [64] and may explain the unexpectedly easy weaning after the surgical procedure. 


\section{Respiratory muscle strength and interaction}

Inspiratory muscle strength is reduced in severe emphysema. As outlined above, this is mostly due to hyperinflation. Moreover, COPD is often associated with a generalized muscle weakness that may also contribute to the reduced respiratory muscle strength [81].

Global inspiratory muscle strength, as measured by mouth pressure during maximal inspiratory efforts $[51,53$, $62]$ or sniff nasal inspiratory pressure [62], has been shown to increase significantly after LVRS. One study did not show any significant improvement in maximal inspiratory pressure [48] but it was not designed to specifically address respiratory muscle function. Diaphragmatic strength evaluated by maximal inspiratory [51] or sniff nasal transdiaphragmatic pressure [62] improved after surgery. These results are generally ascribed to a reduction of hyperinflation as reflected by the lowered FRC observed after LVRS. The effects of reduced hyperinflation on the length and geometry of the different inspiratory muscles remain, however, largely unknown. An increase in diaphragm length after LVRS has been reported using measurements on chest radiographs [82]. Nevertheless, if the length adaptation occurs in patients with chronic hyperinflation and consequently optimal muscle length is achieved near FRC before LVRS, the greater length of the diaphragmatic fibres after surgery would no longer be optimal. This would imply a short-term detrimental effect of the surgical procedure. In the long-term, this is probably less significant because the length adaptation is a reciprocal phenomenon, i.e. the chronic shortening of a muscle leads to a loss of sarcomeres whereas a chronic lengthening is followed by addition of new sarcomeres [83].

Moreover, it should be stressed that the length-tension curve refers to isometric conditions which clearly differ from those encountered in vivo. In emphysematous hamsters, the transdiaphragmatic pressure generated by phrenic nerve stimulation is in fact greater at RV than at FRC [84], demonstrating that in this model, a reduction of FRC would probably be beneficial in terms of diaphragmatic function. At present, it is, however, unclear which are the exact factors underlying the beneficial effects of LVRS on the diaphragmatic and global inspiratory muscle function. On a long-term basis, a favourable effect of an increased length of the diaphragm is likely, but the role of other factors such as the geometry of the respiratory muscles and their mechanical arrangement still need to be explored. Preliminary results demonstrating an increased zone of apposition of the diaphragm after LVRS [82] support a positive effect of the surgical procedure on muscle geometry.

The only study of the effects of LVRS on the ribcage diameters, which are believed to be a determinant of the intercostal muscles function, has resulted in conflicting results. Indeed, LANDO et al. [85] reported a small reduction of the anteroposterior diameter of the mid and lower bony thorax on chest radiograph but they were unable to confirm these results on computed tomography scan (CT). Measurements of the angle between the intercostals and the midline and between the ribs and the sternum were unfortunately not performed.

Whatever the mechanisms underlying the increase in maximal strength of the inspiratory muscles, it may be an important determinant of the decreased dyspnoea after
LVRS. Indeed, the ratio of end-tidal pleural pressure to minimal (i.e. most negative) inspiratory pressure is an important contributing factor to the sensation of breathlessness [86]. In fact, not only is the denominator of this ratio increased after LVRS, but the numerator is also reduced (see below). Nevertheless, no correlation has been found between the increase in maximal inspiratory muscle strength and the improvement in dyspnoea after LVRS [51, 62].

LVRS has been shown to result in a marked change in the relative contributions of the diaphragm and the other respiratory muscles to pressure and volume generation during breathing. Using plots of oesophageal versus gastric pressure during tidal breathing, it has been demonstrated that, before surgery, severe emphysematous patients show large inspiratory decreases in oesophageal pressure during inspiration $[51,61]$ whereas the end-inspiratory gastric pressure does not change [61] or is even reduced compared to the end-expiratory value [51] (fig. 3a). The latter finding possibly reflects a paradoxical movement of the abdomen during the respiratory cycle, but it is more probable that abdominal muscles relax during inspiration after being extensively recruited during expiration. This is supported by the high values of end-expiratory gastric pressure in these two studies $[51,61]$. After surgery, there was a decrease in pleural pressure swings, essentially owing to a decrease in end-expiratory positive oesophageal pressure whereas the abdominal pressure returned to a more normal pattern, showing an increase during the inspiratory phase $[51,61]$ and demonstrating either a greater recruitment of the diaphragm after surgery or a lesser expiratory recruitment of the abdominal muscles. The magnitude of these changes was correlated with the reduction in FRC [61].

Using respiratory inductive plethysmography, BLOCH et al. [57] studied the pattern of motion of the thoracoabdominal wall during resting breathing. They showed that LVRS resulted in a decrease in paradoxical motion of the abdomen during inspiration and in an increase in the contribution of the abdominal volume changes to tidal volume $(\mathrm{Ab} / V \mathrm{~T})$ [57]. They ascribed the latter finding to a greater contribution of the diaphragm to tidal volume generation. Analysis of the individual data demonstrates that four out of 19 patients showed a clear deterioration of these indices of thoracoabdominal wall motion. Although this assumption may be tempting, the absence of an increase of $\mathrm{Ab} / V \mathrm{~T}$ after LVRS in some patients must, however, not necessarily be seen as detrimental. Indeed, it may be related to a derecruitment of the abdominal muscles. In other words, if it is postulated that abdominal muscle recruitment always decreases after LVRS, the improvement in active diaphragm contribution to tidal volume will be underestimated if only abdominal volume changes are considered. Another interesting finding of the study of BLOCH et al. [57] was that patients with a similar degree of hyperinflation (same TLC, RV, and RV/TLC) had a greater improvement in FEV1 and a greater decrease in RV after LVRS, if they had a greater $\mathrm{Ab} / V \mathrm{~T}$ before surgery. This might be regarded as controversial since $\mathrm{Ab} / V \mathrm{~T}$ increases with LVRS. Without knowledge of the relative contribution of expiratory abdominal muscle contraction to the abdominal volume changes, these results are, however, difficult to interpret.

Although the mechanisms relating the preoperative pattern of thoracoabdominal motion to the results of LVRS in terms of FEV1 deserve more study, these findings show 

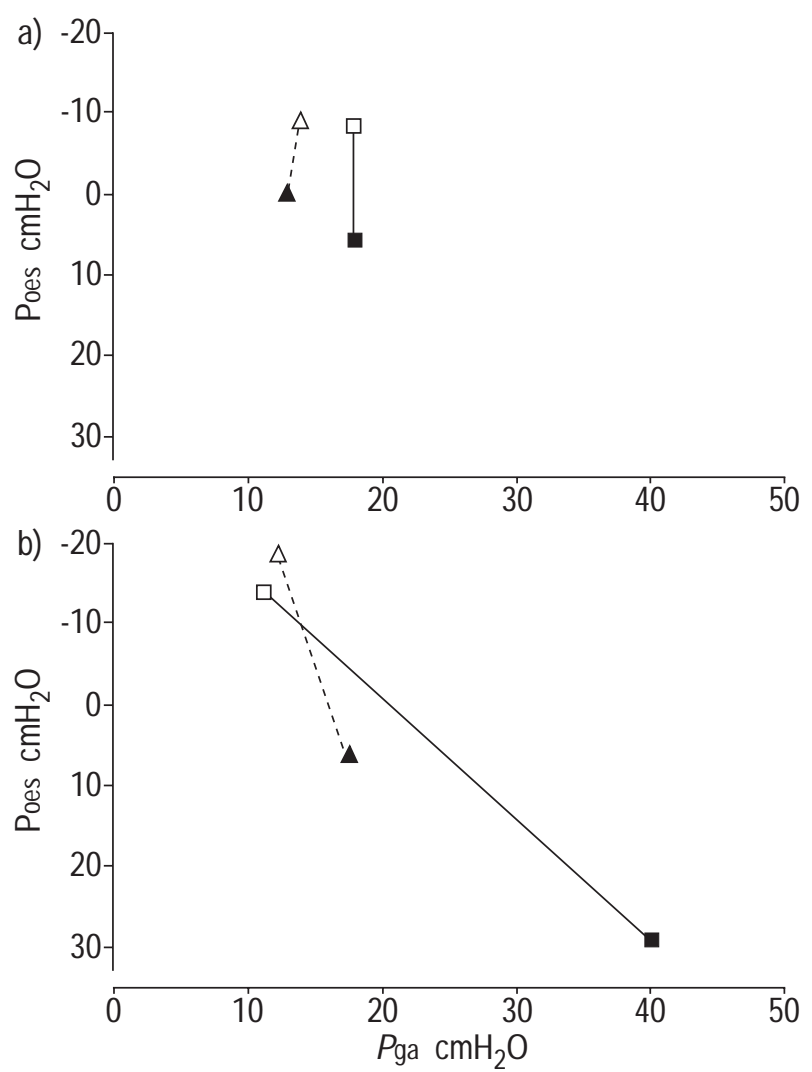

Fig. 3. - Plots of end-inspiratory $(\square, \triangle)$ and end-expiratory ( $\square, \boldsymbol{\Delta})$ gastric pressure $\left(P_{\text {ga }}\right)$ versus oesophageal pressure $\left(P_{\text {oes }}\right)$ at a) rest and during $\mathrm{b}$ ) isowatt exercise before $(-)$ and after (- - -) lung volume reduction surgery. (From BENDITT et al. [61] with permission.)

that the high contribution of the ribcage muscles to tidal volume seen in severe emphysema is reduced by LVRS. As there is some evidence of a relationship between inspiratory ribcage muscle activation and the sensation of breathlessness in patients with airway obstruction $[87,88]$ or during loaded breathing in normal subjects [89], this effect of LVRS towards a more normal pattern of respiratory muscle action may also play a role in the reduced dyspnoea.

\section{Control of breathing and breathing pattern}

Mouth occlusion pressure $0.1 \mathrm{~s}$ after the beginning of inspiration $\left(P_{0.1}\right)$, an index of central inspiratory drive, has been shown to decrease after LVRS [62,90]. A decreased central drive response to the hypercapnic stimulus was also demonstrated [90]. The determinants of increased $P_{0.1}$ in COPD are not fully understood. CELLI et al. [90] hypothesized that the reduced hyperinflation achieved by LVRS was responsible for the reduced central drive and hence, for the decreased breathlessness. Potential mechanisms of the reduction in $P_{0.1}$ after LVRS are a reduced respiratory impedance [90] and an improved inspiratory muscle effectiveness. However, the change in $P_{0.1}$ correlated neither with the change in lung function $[62,90]$ nor with the decrease in dyspnoea after LVRS [62].

BLOCH et al. [57] studied the resting pattern of breathing using respiratory inductive plethysmography. This is thought to alter the mode of breathing less than methods using mouthpieces or facemasks [91]. They showed that emphysematous patients selected for LVRS had a higher minute ventilation than normal subjects in the supine position. There was a tendency for increased respiratory rate and tidal volume whereas the inspiratory time was reduced in emphysema. LVRS had no significant effect on these parameters at rest but as outlined above, the ventilation was achieved with a modified contribution of the diaphragm and the inspiratory ribcage muscles [57]. Other groups have confirmed the lack of effect of LVRS on resting minute ventilation, respiratory rate and tidal breathing using a mouthpiece $[41,61,64]$.

\section{Breathing during exercise}

LVRS has been shown to improve maximal exercise capacity $[41,42,48,51,59]$. Although the majority of the patients included in these studies underwent a pulmonary rehabilitation programme, it seems that factors other than peripheral muscle training are responsible for the improvement. In contrast to rehabilitation, which essentially lowers the ventilatory requirement but does not affect maximal ventilation, LVRS has been shown to increase the maximal ventilatory capacity. Indeed, both maximal voluntary ventilation (MVV) [41, 48, 51, 52, 59] and maximal minute ventilation ( $V^{\prime}$ E,max) at peak exercise $[41,42,48,59$, $61]$ significantly increased after LVRS. This increase in $V^{\prime}$ E,max was entirely due to an increase in tidal volume, since the respiratory rate did not change $[41,48,51,59$, 61]. At isowork exercise, the minute ventilation is either unchanged $[41,51]$ or slightly increased (but with a greater ventilatory reserve) $[59,61]$ after LVRS. Nevertheless, the pattern of breathing is markedly modified with an increase in tidal volume and a decrease in respiratory rate $[51,59$, $61]$. The duty cycle (inspiratory time $(t I) /$ breath duration $(t$ tot $))$ is not modified at peak exercise $[48,51,61]$. At isowork exercise, it was reported to increase by BENDITT et al. [61] while MARTINEZ et al. [51] reported no significant change.

Moreover, as also demonstrated at rest, the recruitment of inspiratory muscles was reported to be altered during exercise with a greater contribution of the diaphragm to inspiratory pressure generation (as shown by an increased inspiratory transdiaphragmatic pressure) and a probable reduction of abdominal muscle recruitment during isowork exercise after surgery (fig. 3b) [51, 61]. This is likely related to a reduced dynamic hyperinflation during isowork exercise, as reflected by an increased inspiratory capacity [51].

Overall, LVRS appears to: 1) increase maximal ventilatory capacity, thereby improving the ventilatory reserve at a given work load; 2) reduce shallow breathing for a given load, thus lowering the dead space to tidal volume ratio; and 3) increase the diaphragmatic contribution to inspiratory pressure generation during exercise, likely through a reduction of dynamic hyperinflation. All these factors have potential beneficial effects on exercise capacity and dyspnoea.

\section{Gas exchange}

Not much is known regarding the mechanisms of improvement in the resting blood gases reported after LVRS in some studies. As a significant improvement in $\mathrm{Pa}_{\mathrm{a}} \mathrm{CO}_{2}$ has sometimes been reported, it should be assumed that, if resting carbon dioxide production remains unchanged, the 
alveolar ventilation may increase after LVRS. As outlined above, the minute ventilation and tidal volume do not change significantly at rest $[41,57,61,64]$, and the improved alveolar ventilation would thus be related to a reduced dead space ventilation. Other potential determinants of $P \mathrm{a}, \mathrm{O}_{2}$ have not yet been studied. Indeed, the effects of LVRS on the ventilation-perfusion matching and on $P_{\mathrm{v}, \mathrm{O}_{2}}^{-}$remain unknown.

It should be noted that $\mathrm{Sa}, \mathrm{O}_{2}$ measured by pulse oximetry did not change significantly during isowatt exercise in two studies [53, 61]. At maximal exercise (and thus at different workloads), BENDiTT et al. [41] did not show any significant improvement in $\mathrm{Pa}_{2} \mathrm{O}_{2}$ after LVRS. Nevertheless, with 16 patients demonstrating respiratory acidosis at peak exercise, this disappeared in two after surgery [41]. This is probably due to the reduced dead space to tidal ventilation ratio demonstrated during exercise after LVRS. However the persisting exercise-induced hypercapnia in a majority of patients points to derangements remaining after surgery.

\section{Haemodynamics and cardiac function}

Data on the influence of LVRS on haemodynamics and cardiac function are scarce. SCIURBA et al. [67] reported an improved resting right ventricular systolic function, evaluated by echocardiography, after LVRS. Similar results were reported by MATHER et al. [92]. These results may lead to the hypothesis that LVRS reduces pulmonary artery pressure and resistance. Nevertheless, preliminary results from OswaLD et al. [93] show that resting mean pulmonary artery pressure did not diminish significantly after surgery. The cardiac index was also unchanged at rest. However, during steady state exercise, the mean arterial pulmonary pressure was significantly decreased while cardiac index remained unchanged [93]. This means that LVRS induced a reduction of exercise pulmonary vascular resistance. As dynamic hyperinflation plays a role in the rise in pulmonary vascular resistance in COPD patients [94], the reduction of exercise-induced dynamic hyperinflation [51] may be an important determinant of the lowered pulmonary artery pressure after LVRS.

The oxygen pulse, a noninvasive estimate of the cardiac stroke volume, has been shown to increase during isowork exercise after LVRS in two studies [41, 59], although this reached statistical significance in only one of the two [59]. Potential determinants of improved cardiac function after LVRS are the demonstrated reduction in pleural pressure swings during the respiratory cycle $[51,61]$ and a yet unproven reduction in resting pulmonary vascular resistance. Improved cardiac function may contribute to the increased exercise capacity. Moreover, it may also play a role in the improvement in $\mathrm{Pa}, \mathrm{O}_{2}$ through an increase in $P_{\mathrm{v}, \mathrm{O}_{2}}$. The effects of LVRS on haemodynamics and cardiac function are clearly to be more thoroughly explored.

\section{Long-term outcome after lung volume reduction surgery}

Data on the long-term functional outcome after LVRS remain scarce. From the literature, it appears that the peak improvement in usual pulmonary function tests probably occurs between 3 and 12 months after surgery [43, 45, 58, $59,66,95]$. GeLB et al. [66] demonstrated that the subsequent deterioration of the functional test results was associated with a decrease in elastic recoil. Nevertheless, 2 yrs after surgery, a clear improvement remained as compared to baseline $[43,96]$. The rate of the functional deterioration after the peak improvement remains unknown.

It has been advocated that the remaining diseased lung after surgery may undergo stress relaxation which could lead to a subsequent progressive decline in elastic recoil and potentially to a rapid decline in FEV1 and conductance [97]. Although stress relaxation is a known phenomenon in the human lung, it has been shown to occur only in the short-term [98]. Whether it may develop in the long-term is not known.

The effects of LVRS on maximal exercise capacity also seem to peak around 6 months after surgery [59] but the improvement in submaximal exercise performance [43, 68] and quality of life [59] are sustained up to one year. However, the respective effects of LVRS and pulmonary rehabilitation on these variables are difficult to assess.

\section{Future prospects}

All the results reported above are average results of often selected groups of patients. This should not obscure the fact that up to $20 \%$ of the patients do not experience an improvement either subjectively or in the pulmonary function tests $[4,39,41,42,45-48,51,52,54,57,61,62]$ and that mortality is not negligible $[4,39,40,43,47,49$, $50,52,54,58,99]$, reaching $10 \%$ in some series [49]. The determinants of outcome have not yet received much attention. This clearly necessitates outcome measures to be defined. FEV1 is often viewed as an important outcome measure in lung diseases. We must however remember that LVRS is currently accepted as a procedure aimed at alleviating the symptoms of advanced emphysema. It is well known that breathlessness only correlates weakly with FEV1 and after LVRS the improvement of FEV1 also poorly predicts the reduction of dyspnoea. Outcome measures should thus not be limited to usual pulmonary function tests.

Until now, the study of the effects of LVRS on gas exchange as well as on the pulmonary and systemic haemodynamics has been very limited. A better knowledge of these effects could further improve the understanding of the functional improvement achieved by LVRS. Furthermore, a more precise understanding of the determinants underlying the improvement of elastic lung recoil and respiratory muscle function is required. The development of an animal model of LVRS clearly would help to shed light on these mechanisms.

\section{Summary}

The rapid development of lung volume reduction surgery and of its utilization has allowed a better understanding of the basic mechanisms of the objective and subjective improvement experienced by a majority of selected patients. Two major effects of the surgery are responsible for this favourable early outcome: an increase in lung elastic recoil and a reduction in lung volume obtained by the resection of lung emphysematous tissue and, indirectly, by the partial recovery of the elastic recoil (table 1). The reduction of the lung volume at which they operate has a dramatic effect on respiratory muscle function and interaction as well as on the work of breathing and may probably by itself explain a great part of the decreased breathlessness observed after surgery. The improved lung recoil certainly plays a central role in the 
Table 1. - Summary of the physiological effects of lung volume reduction surgery

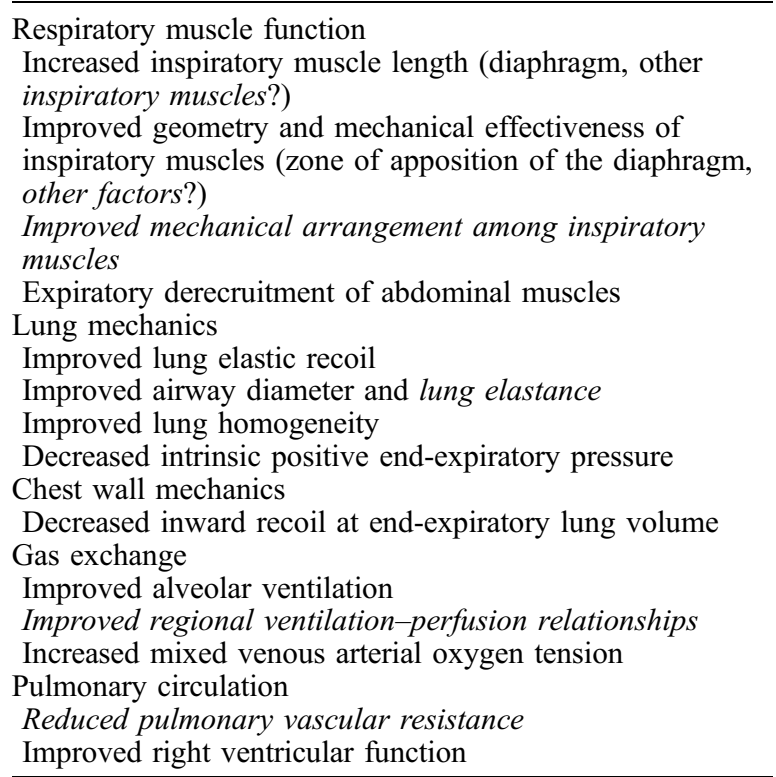

Established effects of lung volume reduction surgery are displayed in normal type and hypothetical effects in italic type.

reduction of the airway obstruction and its consequences. Nevertheless, the mechanism of improved elastic recoil is still poorly understood and it is possible that other factors currently remaining undefined also play a role in a better airway function after LVRS. Similarly, the mechanisms underlying the improved respiratory muscle function are still to be established. The effects of LVRS on gas exchange as well as on haemodynamics remain to be studied more thoroughly, as well as the long-term effect of the procedure. It is now proven that the primary postulates upon which the selection process for lung volume reduction surgery were based are correct. However, this is only true based on an average basis and some patients, although selected following the same criteria, do not benefit from the procedure. An analysis of the characteristics of these patients would possibly help to refine the selection criteria. However, a more profound investigation of the mechanisms underlying the improved elastic recoil, airway function and respiratory muscle function appears essential to achieve this goal.

\section{References}

1. Brantigan OC, Mueller E, Kress MB. A surgical approach to pulmonary emphysema. Am Rev Respir Dis 1959; 80: 194-202.

2. Cooper JD, Trulock EP, Triantafillou AN, et al. Bilateral pneumectomy (volume reduction) for chronic obstructive pulmonary disease. J Thorac Cardiovasc Surg 1995; 109: 106-119.

3. Wakabayashi A, Brenner M, Kayaleh RA, et al. Thoracoscopic carbon dioxide laser treatment of bullous emphysema. Lancet 1991; 337: 881-883.

4. Wakabayashi A. Thoracoscopic laser pneumoplasty in the treatment of diffuse bullous emphysema. Ann Thorac Surg 1995; 60: 936-942.

5. Make BJ, Fein AM. Is volume reduction surgery ap- propriate in the treatment of emphysema? No. Am J Respir Crit Care Med 1996; 153: 1205-1207.

6. Sciurba FC. Early and long-term functional outcomes following lung volume reduction surgery. Clin Chest Med 1997; 18: 259-276.

7. American Thoracic Society. Chronic bronchitis, asthma, and pulmonary emphysema: a statement by the Committee on Diagnostic Standards for Nontuberculous Respiratory Diseases. Am Rev Respir Dis 1962; 85: 762-768.

8. Mead J, Turner JM, Macklem PT, Little JB. Significance of the relationship between lung recoil and maximum expiratory flow. J Appl Physiol 1967; 22: 95-108.

9. Dayman H. Mechanics of airflow in health and in emphysema. J Clin Invest 1951; 30: 1175-1190.

10. Kim WD, Eidelman DH, Izquierdo JL, Ghezzo H, Saetta MP, Cosio MG. Centrilobular and panlobular emphysema in smokers. Two distinct morphologic and functional entities. Am Rev Respir Dis 1991; 144: 1385-1390.

11. Saetta M, Kim WD, Izquierdo JL, Ghezzo H, Cosio MG. Extent of centrilobular and panacinar emphysema in smokers' lungs: pathological and mechanical implications. Eur Respir J 1994; 7: 664-671.

12. Pellegrino R, Brusasco V. Lung hyperinflation and flow limitation in chronic airway obstruction. Eur Respir $J$ 1997; 10: 543-549.

13. Ranieri VM, Grasso S, Fiore T, Giuliani R. Auto-positive end-expiratory pressure and dynamic hyperinflation. Clin Chest Med 1996; 17: 379-394.

14. Cassart M, Pettiaux N, Gevenois PA, Paiva M, Estenne M. Effect of chronic hyperinflation on diaphragm length and surface area. Am J Respir Crit Care Med 1997; 156: 504-508.

15. Farkas GA, Roussos C. Diaphragm in emphysematous hamsters: sarcomere adaptability. J Appl Physiol: Respir Environ Exercise Physiol 1983; 54: 1635-1640.

16. Similowski T, Yan S, Gauthier AP, Macklem PT, Bellemare F. Contractile properties of the human diaphragm during chronic hyperinflation. $N$ Engl $J$ Med 1991; 325: 917-923.

17. Gauthier AP, Verbanck S, Estenne M, Segebarth C, Macklem PT, Paiva M. Three dimensional reconstruction of the in vivo human diaphragm shape at different lung volumes. J Appl Physiol 1994; 76: 495-506.

18. De Troyer A. Effect of hyperinflation on the diaphragm. Eur Respir J 1997; 10: 708-713.

19. Macklem PT, Macklem DM, De Troyer A. A model of inspiratory muscle mechanics. J Appl Physiol: Respir Environ Exercise Physiol 1983; 55: 547-557.

20. Ninane V, Gorini M. Adverse effects of hyperinflation on parasternal intercostals. J Appl Physiol 1994; 77: 22012206.

21. De Troyer A, Legrand A. Inhomogeneous activation of the parasternal intercostals during breathing. J Appl Physiol 1995; 79: 55-62.

22. Farkas G, Decramer M, Rochester DF, De Troyer A. Contractile properties of intercostal muscles and their functional significance. J Appl Physiol 1985; 59: 528-535.

23. Decramer M. Respiratory muscle interaction during acute and chronic hyperinflation. Monaldi Arch Chest Dis 1993; 48: 483-488.

24. Cassart M, Gevenois PA, Estenne M. Rib cage dimensions in hyperinflated patients with severe chronic obstructive pulmonary disease. Am J Respir Crit Care Med 1996; 154: 800-805.

25. De Troyer A, Estenne M. Coordination between rib cage muscles and diaphragm during quiet breathing in humans. 
J Appl Physiol: Respir Environ Exercise Physiol 1984; 57: 899-906.

26. Gandevia SC, Leeper JB, McKenzie DK, De Troyer A. Discharge frequencies of parasternal intercostal and scalene motor units during breathing in normal and COPD subjects. Am J Respir Crit Care Med 1996; 153: 622-628.

27. Farkas GA, Rochester DF. Contractile characteristics and operating lengths of canine neck inspiratory muscles. $J$ Appl Physiol 1986; 61: 220-226.

28. Ninane V, Rypens F, Yernault JC, De Troyer A. Abdominal muscle use during breathing in patients with chronic airflow obstruction. Am Rev Respir Dis 1992; 146: 16-21.

29. Ninane V, Yernault JC, De Troyer A. Intrinsic PEEP in patients with chronic obstructive pulmonary disease. Role of expiratory muscles. Am Rev Respir Dis 1993; 148: 1037-1042.

30. Sharp JT, Beard GAT, Sunga M, et al. The rib cage in normal and emphysematous subjects: a roentgenographic approach. J Appl Physiol 1986; 61: 2050-2059.

31. Dodd DS, Brancatisano T, Engel LA. Chest wall mechanics during exercise in patients with severe chronic air-flow obstruction. Am Rev Respir Dis 1984; 129: 3338.

32. Macklem PT. Hyperinflation. Am Rev Respir Dis 1984; 129: 1-2.

33. Decramer M. Hyperinflation and respiratory muscle interaction. Eur Respir J 1997; 10: 934-941.

34. Wagner PD, Dantzker DR, Clausen JL, West JB. Ventilation-perfusion inequality in chronic obstructive pulmonary disease. J Clin Invest 1977; 59: 203-216.

35. Gallagher CG. Exercise limitation and clinical exercise testing in chronic obstructive pulmonary disease. Clin Chest Med 1994; 15: 305-326.

36. Wagner PD, Gale GE. Ventilation-perfusion relationships. In: Whipp BJ, Wasserman K, eds. Exercise. Pulmonary Physiology and Pathophysiology. New York, Marcel Dekker, 1991; pp121-142.

37. Gosselink R, Troosters T, Decramer M. Peripheral muscle weakness contributes to exercise limitation in COPD. Am J Respir Crit Care Med 1996; 153: 976-980.

38. Mahler DA, Faryniarz K, Tomlinson D. Impact of dyspnea and physiologic function on general health status in patients with chronic obstructive pulmonary disease. Chest 1992; 102: 395-401.

39. Halzerigg S, Boley T, Henkle J, et al. Thoracoscopic laser bullectomy: a prospective study with three-month results. J Thorac Cardiovasc Surg 1996; 112: 319-327.

40. Argenziano M, Moazami N, Thomashow B. Extended indications for lung volume reduction surgery in advanced emphysema. Ann Thorac Surg 1996; 62: 1588-1597.

41. Benditt JO, Lewis S, Wood DE, Klima L, Albert RK. Lung volume reduction surgery improves maximal $\mathrm{O}_{2}$ consumption, maximal minute ventilation, $\mathrm{O}_{2}$ pulse, and dead space-to-tidal volume ratio during leg cycle ergometry. Am J Respir Crit Care Med 1997; 156: 561-566.

42. Bingisser R, Zollinger A, Hauser M, Bloch KE, Russi $\mathrm{EW}$, Weder W. Bilateral volume reduction surgery for diffuse pulmonary emphysema by video-assisted thoracoscopy. J Thorac Cardiovasc Surg 1996; 112: 875-882.

43. Cooper JD, Patterson GA, Sundaresan RS, et al. Results of 150 consecutive bilateral lung volume reduction procedures in patients with severe emphysema. $J$ Thorac Cardiovasc Surg 1996; 112: 1319-1330.

44. Daniel TM, Chan BK, Bhaskar V, et al. Lung volume reduction surgery. Case selection, operative technique, and clinical results. Ann Surg 1996; 223: 526-533.
45. Roué C, Mal H, Sleiman C, et al. Lung volume reduction in patients with severe diffuse emphysema. A retrospective study. Chest 1996; 110: 28-34.

46. McKenna RJJ, Brenner M, Gelb AF, et al. A randomized, prospective trial of stapled lung reduction versus laser bullectomy for diffuse emphysema. $J$ Thorac Cardiovasc Surg 1996; 111: 317-322.

47. McKenna RJJ, Brenner M, Fischel R, Gelb AF. Should lung volume reduction for emphysema be unilateral or bilateral? J Thorac Cardiovasc Surg 1996; 112: 13311339.

48. Keller CA, Ruppel G, Hibbett A, Osterloh J, Naunheim KS. Thoracoscopic lung volume reduction surgery reduces dyspnea and improves exercise capacity in patients with emphysema. Am J Respir Crit Care Med 1997; 156: 60-67.

49. Kotloff RM, Tino G, Bavaria JE, et al. Bilateral lung volume reduction surgery for advanced emphysema. A comparison of median sternotomy and thoracoscopic approaches. Chest 1996; 110: 1399-1406.

50. Little AG, Swain JA, Nino JJ, Prabhu RD, Schlachter MD, Barcia TC. Reduction pneumoplasty for emphysema. Early results. Ann Surg 1995; 222: 365-374.

51. Martinez FJ, Montes de Oca M, Whyte RI, Stetz J, Gay SE, Celli BR. Lung-volume reduction improves dyspnea, dynamic hyperinflation, and respiratory muscle function. Am J Respir Crit Care Med 1997; 155: 1984-1990.

52. Miller JI, Lee RB, Mansour KA. Lung volume reduction surgery: lessons learned. Ann Thorac Surg 1996; 61: 1464-1469.

53. O'Donnell DE, Webb KA, Bertley JC, Chau LKL, Conlan AA. Mechanisms of relief of exertional breathlessness following unilateral bullectomy and lung volume reduction surgery in emphysema. Chest 1996; 110: 18-27.

54. Keenan RJ, Landreneau RJ, Sciurba FC, et al. Unilateral thoracoscopic surgical approach for diffuse emphysema. $J$ Thorac Cardiovasc Surg 1996; 111: 308-316.

55. Swanson SJ, Mentzer SJ, DeCamp MMJ, et al. No-cut thoracoscopic lung plication: a new technique for lung volume reduction surgery. J Am Coll Surg 1997; 185: 2532.

56. Teschler H, Stamatis G, Farhat AA, et al. Funktionelle Ergebnisse der chirurgischen Lungenvolumen-reduktion beim schweren Lungenemphysem. Dtsch Med Wschr 1996; 121: 1248-1254.

57. Bloch KE, Li Y, Zhang J, et al. Effect of surgical lung volume reduction on breathing patterns in severe pulmonary emphysema. Am J Respir Crit Care Med 1997; 156: $553-560$.

58. Wisser W, Tschernko EM, Wanke T, et al. Functional improvements in ventilatory mechanics after lung volume reduction surgery for homogeneous emphysema. Eur $J$ Cardio Thorac Surg 1997; 12: 525-530.

59. Cordova F, O'Brien G, Furukawa S, Kuzma AM, Travaline J, Criner GJ. Stability of improvements in exercise performance and quality of life following bilateral lung volume reduction surgery in severe COPD. Chest 1997; 112: 907-915.

60. Brenner M, McKenna RJ, Gelb AF, et al. Dyspnea response following bilateral thoracoscopic staple lung volume reduction surgery. Chest 1997; 112: 916-923.

61. Benditt JO, Wood DE, McCool FD, Lewis S, Albert RK. Changes in breathing and ventilatory muscle recruitment patterns induced by lung volume reduction surgery. $\mathrm{Am} \mathrm{J}$ Respir Crit Care Med 1997; 155: 279-284.

62. Teschler H, Stamatis G, El-Raouf Farhat AA, Meyer FJ, Costabel U, Konietzko N. Effect of surgical lung volume 
reduction on respiratory muscle function in pulmonary emphysema. Eur Respir J 1996; 9: 1779-1784.

63. Gelb AF, McKenna RJJ, Brenner M, Fischel R, Baydur A, Zamel N. Contribution of lung and chest wall mechanics following emphysema resection. Chest 1996; 110: 11-17.

64. Tschernko EM, Wisser W, Wanke T, et al. Changes in ventilatory mechanics and diaphragmatic function after lung volume reduction surgery in patients with COPD. Thorax 1997; 52: 545-550.

65. Weinmann GG, Hyatt R. Evaluation and research in lung volume reduction surgery. Am J Respir Crit Care Med 1996; 154: 1913-1918

66. Gelb AF, Brenner M, McKenna RJJ, Zamel N, Fischel R, Epstein JD. Lung function 12 months following emphysema resection. Chest 1996; 110: 1407-1415.

67. Sciurba FC, Rogers RM, Keenan RJ, et al. Improvement in pulmonary function and elastic recoil after lung-reduction surgery for diffuse emphysema. $N$ Engl $J$ Med 1996; 334: 1095-1099.

68. Gaissert HA, Trulock EP, Cooper JD, Sundaresan RS, Patterson GA. Comparison of early functional results after volume reduction or lung transplantation for chronic obstructive pulmonary disease. J Thorac Cardiovasc Surg 1996; 111: 296-307.

69. Holbert JM, Brown ML, Sciurba FC, Keenan RJ, Landreneau RJ, Holzer AD. Changes in lung volume and volume of emphysema after unilateral lung reduction surgery: analysis with CT lung densitometry. Radiology 1996; 201: 793-797.

70. Butler CW, Benditt JO, Lewis SL, Wood DE, Albert RK. Lung volume reduction surgery improves quality of life as measured by both general and disease-specific instruments. Am J Respir Crit Care Med 1997; 155: A794.

71. Gelb AF, Zamel N, McKenna RJJ, Brenner M. Mechanism of short-term improvement in lung function after emphysema resection. Am J Respir Crit Care Med 1996; 154: 945-951.

72. Pride NB, Macklem PT. Lung mechanics in disease. In: Handbook of Physiology. Section 3. The Respiratory System. Volume 3: Mechanics of Breathing. Part 2. Bethesda, MD, American Physiological Society, 1986; pp. 659-692.

73. Berend N, Woolcock AJ, Marlin GE. Effects of lobectomy on lung function. Thorax 1980; 35: 145-150.

74. Pride NB, Barter CE, Hugh-Jones P. The ventilation of bullae and the effect of their removal on thoracic gas volumes and tests of over-all pulmonary function. $\mathrm{Am} \mathrm{Rev}$ Respir Dis 1973; 107: 83-98.

75. Rogers RM, DuBois AB, Blakemore WS. Effect of removal of bullae on airway conductance and conductance volume ratio. J Clin Invest 1968; 47: 2569-2579.

76. Baldwin JC, Fabre J, Chong C, Omessi E, Miller C, Espada R. Heterogeneity index predicts beneficial outcome in lung volume reduction surgery. Eur Respir $J$ 1997; 10: Suppl. 25, 270s-271s.

77. Weder W, Thurnheer R, Stammberger U, Bürge M, Russi EW. Radiological emphysema morphology correlates with outcome of lung volume reduction surgery. Eur Respir J 1997; 10: Suppl. 25, 271s.

78. Rogers RM, Sciurba FC, Rogers WB, Slivka WA, Keenan RJ. Improvement in airway conductance-volume ratios related to improvements in lung elastic recoil following lung volume reduction surgery. Am J Respir Crit Care Med 1997; 155: A602.

79. Hohlfeld J, Fabel H, Hamm H. The role of pulmonary surfactant in obstructive airways disease. Eur Respir $J$ 1997; 10: 482-491.

80. Harris SP, Sciurba FC, Slivka WA, Rogers RM, Stewart
CJ, Keenan RJ. Improved single breath gas distribution following lung volume reduction surgery. Am J Respir Crit Care Med 1997; 155: A607.

81. Tobin MJ. Respiratory muscles in disease. Clin Chest Med 1988; 9: 263-286.

82. Lando Y, Boiselle P, Travaline JM, Cordova FC, Shade D, Criner GJ. Effect of lung volume reduction surgery on diaphragm length measured by plain chest radiograph in severe hyperinflated COPD patients. Am J Respir Crit Care Med 1997; 155: A603.

83. Tabary JC, Tabary C, Tardieu C, Tardieu G, Goldspink G. Physiological and structural changes in the cat's soleus muscle due to immobilization at different lengths by plaster casts. J Physiol (Lond) 1974; 224: 231-244.

84. Oliven A, Supinski GS, Kelsen SG. Functional adaptation of diaphragm to chronic hyperinflation in emphysematous hamsters. J Appl Physiol 1986; 60: 225-231.

85. Lando Y, Boiselle P, Travaline JM, Cordova FC, Shade D, Criner GJ. Bony thorax configuration after lung volume reduction surgery (LVRS) in severe COPD. Am J Respir Crit Care Med 1997; 155: A603.

86. Leblanc P, Bowie DM, Summers E, Jones NL, Killian KJ. Breathlessness and exercise in patients with cardiorespiratory disease. Am Rev Respir Dis 1986; 133: 21-25.

87. McFadden ER, Kiser R, DeGroot WJ. Acute bronchial asthma. Relations between clinical and physiologic manifestations. N Engl J Med 1973; 288: 221-225.

88. Celli BR, Rassulo J, Make BJ. Dyssynchronous breathing during arm but not exercise in patients with chronic airflow obstruction. N Engl J Med 1986; 314: 1485-1490.

89. Ward ME, Eidelman D, Stubbing DG, Bellemare F, Macklem PT. Respiratory sensation and pattern of respiratory muscle activation during fatigue. $J$ Appl Physiol 1988; 65: 2181-2189.

90. Celli BR, Montes de Oca M, Mendez R, Stetz J. Lung reduction surgery in severe COPD decreases central drive and ventilatory response to $\mathrm{CO}_{2}$. Chest $1997 ; 112$ : $902-$ 906.

91. Loveridge B, West P, Anthonisen NR, Kryger MH. Breathing patterns in patients with chronic obstructive pulmonary disease. Am Rev Respir Dis 1984; 130: 730-733.

92. Mather PJ, O'Brien G, Kuzma AM, Furukawa S, Criner GJ. Functional adaptation of the right ventricle following bilateral lung volume reduction surgery. Am J Respir Crit Care Med 1997; 155: A607.

93. Oswald M, Kessler R, Massard G, Wilhm JM, Weitzenblum E. Gasometric and pulmonary hemodynamic data at rest and during exercise after lung volume reduction surgery. Eur Respir J 1997; 10: Suppl. 25, 74s.

94. Schrijen FV, Henriquez A, Carton D, Delorme N, Butler J. Pulmonary vascular resistance rises with lung volume on exercise in obstructed airflow disease. Clin Physiol 1989; 9: 143-150.

95. Stammberger U, Thurnheer R, Bloch KE, Zollinger A, Russi EW, Weder W. Bilateral thoracoscopic volume reduction surgery for pulmonary emphysema - Functional results. Eur Respir J 1997; 10: Suppl. 25, 272s.

96. Yusen RD, Lefrak SS, Pohl MS, et al. Lung volume reduction surgery: two-year outcomes. Am J Respir Crit Care Med 1997; 155: A794.

97. Brenner M, Yusen R, McKenna RJ, et al. Lung volume reduction surgery for emphysema. Chest 1996; 110: 205 218.

98. Marshall R, Widdicombe JG. Stress relaxation of the human lung. Clin Sci 1960; 20: 19-31.

99. Brenner M, McKenna RJ, Gelb A, et al. Objective predictors of response for staple versus laser emphysematous lung reduction. Am J Respir Crit Care Med 1997; 155: 1295-1301. 